\title{
Brain Perivascular Spaces as Biomarkers of Vascular Risk: Results from the Northern Manhattan Study
}

\author{
(D). Gutierrez, (D) M.S.V. Elkind, (D) C. Dong, (D). Di Tullio, (D)T. Rundek, DR.L. Sacco, and (D).B. Wright
}

\begin{abstract}
BACKGROUND AND PURPOSE: Dilated perivascular spaces in the brain are associated with greater arterial pulsatility. We hypothesized that perivascular spaces identify individuals at higher risk for systemic and cerebral vascular events.
\end{abstract}

MATERIALS AND METHODS: Stroke-free participants in the population-based Northern Manhattan Study had brain MR imaging performed and were followed for myocardial infarction, any stroke, and death. Imaging analyses distinguished perivascular spaces from lesions presumably ischemic. Perivascular spaces were further subdivided into lesions with diameters of $\leq 3 \mathrm{~mm}$ (small perivascular spaces) and $>3$ $\mathrm{mm}$ (large perivascular spaces). We calculated relative rates of events with Poisson models and hazard ratios with Cox proportional models.

RESULTS: The Northern Manhattan Study participants who had MR imaging data available for review ( $n=1228 ; 59 \%$ women, 65\% Hispanic; mean age, $71 \pm 9$ years) were followed for an average of $9 \pm 2$ years. Participants in the highest tertile of the small perivascular space score had a higher relative rate of all deaths (relative rate, 1.38; $95 \% \mathrm{Cl}, 1.01-1.91$ ), vascular death (relative rate, 1.87; 95\% Cl, 1.12-3.14), myocardial infarction (relative rate, $2.08 ; 95 \% \mathrm{Cl}, 1.01-4.31$ ), any stroke (relative rate, $1.79 ; 95 \% \mathrm{Cl}, 1.03-3.11$ ), and any vascular event (relative rate, $1.74 ; 95 \%$ $\mathrm{Cl}$ 1.18-2.56). After we adjusted for confounders, there was a higher risk of vascular death (hazard ratio, 1.06; 95\% Cl, 1.01-1.11), myocardial infarction (hazard ratio, 2.22; 95\% Cl, 1.12-4.42), and any vascular event (hazard ratio, 1.04; 95\% Cl, 1.01-1.08) with higher small perivascular space scores.

CONCLUSIONS: In this multiethnic, population-based study, participants with a high burden of small perivascular spaces had increased risk of vascular events. By gaining pathophysiologic insight into the mechanism of perivascular space dilation, we may be able to propose novel therapies to better prevent vascular disorders in the population.

ABBREVIATIONS: $\mathrm{HR}=$ hazard ratio; $\mathrm{LPI}=$ lesions presumably ischemic; $\mathrm{MI}=$ myocardial infarction; $\mathrm{NOMAS}=$ Northern Manhattan Study; $\mathrm{PP}=$ pulse pressure; $\mathrm{PVS}=$ perivascular space; $\mathrm{RR}=$ relative rate; $\mathrm{WMHV}=$ white matter hyperintensity volume

O entering the skull, large arteries of the circle of Willis become encircled by a layer of leptomeninges and pial cells that accompany them through their course in the subarachnoid space and into the brain parenchyma, creating a potential perivascular space (PVS). ${ }^{1-3}$ The physiologic role of these PVSs relates to the drainage of brain interstitial fluid into perivascular pathways,

Received October 11, 2016; accepted after revision January 6, 2017.

From the Departments of Neurology (J.G., M.S.V.E.) and Medicine (M.D.), Columbia University Medical Center, New York, New York; Department of Epidemiology (M.S.V.E.), Mailman School of Public Health, Columbia University, New York, New York; and Department of Neurology (C.D., T.R., R.L.S., C.B.W.), Miller School of Medicine, University of Miami, Miami, Florida.

This work was supported by National Institutes of Health 2R01NS029993-23A1. Please address correspondence to Jose Gutierrez, MD, MPH, 710 W 168th St, 6th floor, Suite 639, New York, NY 10032; e-mail: jg3233@cumc.columbia.edu; @drjosegc

- Indicates open access to non-subscribers at www.ajnr.org

= Indicates article with supplemental on-line tables.

http://dx.doi.org/10.3174/ajnr.A5129 subarachnoid space, and the glymphatic drainage system. ${ }^{1,4}$ Perivascular spaces are heterogeneous in their anatomic and physiologic characteristics. For example, basal ganglia PVSs are anatomically distinct from cortical PVSs, and arterial PVSs differ from venous PVSs. ${ }^{1-3}$ These anatomic differences may have implications for interstitial fluid drainage rates in different brain regions. ${ }^{5,6}$

An increased prevalence of PVSs has been associated with multiple sclerosis, ${ }^{7}$ which may suggest altered clearance of inflammatory cells and exudates from the PVSs. ${ }^{7,8}$ PVSs have also been associated with pulsatile blood hemodynamics and hypertension. $^{6}$ It may be that through these associations, PVSs relate to carotid atherosclerosis, ${ }^{9}$ imaging biomarkers of brain small-artery disease such as white matter hyperintensities, and lacunar stroke, ${ }^{10,11}$ as well as brain atrophy. ${ }^{12,13}$ The coexistence with other imaging biomarkers of small-artery disease, such as lacunar infarcts and white matter disease, which themselves are associated with hypertension, ${ }^{12,14}$ may suggest a shared physiopathology. 
Nonetheless, dilated PVSs have been associated with higher systolic blood pressure and pulse pressure (PP) to a greater extent than other imaging biomarkers of small-artery disease ${ }^{6,15}$; this association suggests a differential role for greater pulsatility as a predisposing factor for these lesions. The validity of dilated PVSs as imaging biomarkers of risk has not been validated prospectively, however, to our knowledge.

Because of the links between PVSs and vascular disease, we tested the hypothesis that brain PVSs are independent imaging biomarkers of vascular risk and that this risk is greater in individuals with high PP and among those with evidence of established non-PVS-related small-artery disease in the Northern Manhattan Study (NOMAS) MR imaging substudy.

\section{MATERIALS AND METHODS}

The NOMAS MR imaging substudy represents a populationbased sample of adults 50 years of age or older at the time of MR imaging who have prospective follow-up. A detailed report of the criteria for enrollment in the NOMAS cohort and the MR imaging substudy has been provided elsewhere. ${ }^{6}$ In brief, participants needed to be free of stroke symptoms at the time of enrollment and had to provide informed consent to undergo brain MR imaging. The study was approved by the local institutional review board (Columbia University and University of Miami). Demographic data were self-reported. Hypertension, diabetes, and hypercholesterolemia were defined at the time of MR imaging and during follow-up by either self-reported diagnoses, medication use to treat these vascular risks, or blood pressure and/or laboratory evidence of these vascular risks, as previously reported. ${ }^{6,9}$ Blood pressure measurements were taken twice ( $>1$ hour apart) at the time of the brain MR imaging. Smoking was defined as self-reported current smoking at the time of MR imaging and during follow-up.

\section{Brain MR Imaging Protocol and Postprocessing}

Imaging was performed on a dedicated $1.5 \mathrm{~T}$ research MR imaging system (Philips Healthcare, Best, the Netherlands). The FLAIR image was acquired in the multisection turbo spin-echo mode with an FOV of $250 \mathrm{~mm}$, rectangular FOV of $80 \%$, acquisition matrix of $192 \times 133$ scaled to $256 \times 256$ in reconstruction, 3-mm section thickness with no gap, a TE of $144 \mathrm{~ms}$, a TR of $5500 \mathrm{~ms}$, an inversion recovery delay of $1900 \mathrm{~ms}$, and a flip angle of $90^{\circ}$. Dilated PVSs have been subdivided into 4 types: type III lacunes, a to d. Dilated PVSs of small diameter (ie, $<3 \mathrm{~mm}$ ) have been called "type III lacunes a" or "criblures," 5 and here we call them small PVSs. They are often numerous, and it is not practical to count them. Consequently, semiquantitative scores have been proposed. ${ }^{14}$ Small PVSs are defined here as brain parenchymal voids observed on axial T1 images of no more than $5 \mathrm{~mm}$ in any axial diameter (Fig 1). ${ }^{16,17}$ A semiquantitative score ranging from 0 to 2 was used to rate 13 separate anatomic areas in the brain, with a possible overall score thus ranging from 0 to 26 . The intra- and interreader reliabilities were excellent (intraclass correlation coefficient $=0.90)$ and good (intraclass correlation coefficient $=$ 0.73). ${ }^{6,9}$ For T1 voids of $>5 \mathrm{~mm}$, we noted their anatomic location and the associated FLAIR characteristics (ie, hyperintense rim) and obtained the longest axial diameter, a diameter perpen-

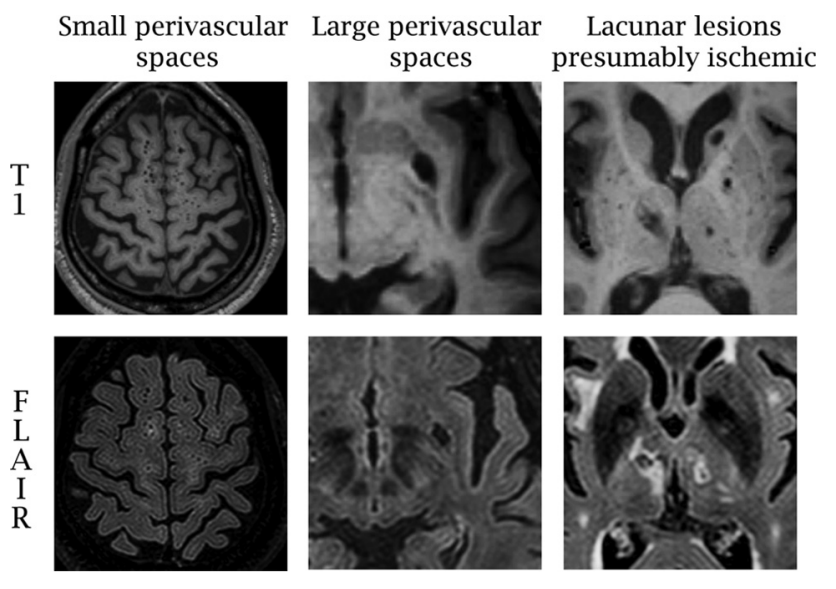

FIG 1. Examples of parenchymal voids rated in the Northern Manhattan Study MR imaging substudy.

dicular to that, and a vertical diameter (multiplying the number of sections by section thickness [ $1.3 \mathrm{~mm}$ in this case]) to account for the rostral path of perivascular spaces. The volume of each large $\mathrm{T} 1$ void was calculated by using the $\mathrm{ABC} / 2$ formula for ovoid bodies, ${ }^{18}$ which yielded a minimum volume-derived diameter of $3 \mathrm{~mm}$. Motion artifacts on T1 were noted as none, mild-to-moderate, or severe. The measurement and visual ratings were performed with 3D Slicer open source software, Version 4.3.1 (http:// www.slicer.org), which permits measurements below the pixel resolution of our scans.

We developed a previously published probabilistic method informed by anatomic-radiologic correlation studies that differentiates subclinical lesions presumably ischemic (LPI) and large PVSs (Fig 1). ${ }^{6}$ Large PVSs correspond to lacunes type IIIb (subcortical or cerebellar) and type IIIc (infraputaminal). ${ }^{5}$ With the shape, anatomic location, and features of the T1 voids, we classified lesions as more likely LPI, large PVS, or uncertain. With these criteria, the FLAIR rim was the dominant feature in determining LPI versus large PVSs, except in the brain stem and the upper two-thirds of the basal ganglia, where pathologic evidence showed that voids in these areas are more likely to represent infarcts. ${ }^{17,19,20}$ Uncertain voids were found in 56 participants and were isolated from LPI or large PVSs in only 9 participants. Due to the lack of confirmatory testing about the nature of these voids, we left them out of this analysis. This method has proved to have moderate-to-good reliability. ${ }^{6,9}$ The total volume of large perivascular spaces was calculated as the sum of the individual volume of each large perivascular space noted per participant, and the large perivascular spaces score consisted of the number of large perivascular spaces per participant.

White matter hyperintensity volume (WMHV), total intracranial volume (ie, head size), and total cerebral volume were obtained automatically with a Quantum 6.2 package on an Ultra 5 workstation (Sun Microsysytems, Santa Clara, California) as described before. Briefly, tracing the dura allowed the removal of brain elements from the scan, keeping anterior and middle cranial fossae but excluding the posterior fossa, resulting in total intracranial volume. Total cerebral volume was computed as the sum of whole-brain volume voxels from the $\mathrm{T} 1$ segmentation process, and white matter hyperintensity volume was calculated as the sum 
of voxels of $\geq 3.5$ SDs above the mean image intensity multiplied by pixel dimensions and section thickness using axial FLAIR images. ${ }^{21}$ For this study, the percentage of atrophy was obtained by using the formula [(Total Intracranial Volume - Total Cerebral Volume) / Total Intracranial Volume $\times 100] .^{22}$

\section{Longitudinal Follow-Up}

Participants in the NOMAS MR imaging substudy are screened annually with standardized telephone interviews and/or in-person visits if the participant was screened positive for a predefined outcome and/or censoring (ie, no outcome reported). The outcomes include any stroke, MI, or death (including cause of death). Any vascular event was defined as a composite of vascular death, any stroke, or myocardial infarction (MI), as described previously. ${ }^{23}$ Briefly, death and vascular death were adjudicated by NOMAS investigators with a negligible loss to follow-up. Most NOMAS participants are admitted for inpatient evaluation in case of major vascular outcomes such as stroke or MI. For participants not admitted to Columbia University Medical Center, we collect their medical records from the reported hospital of admission. Subsequently, stroke subtypes are adjudicated independently by 2 study vascular neurologists (blinded to the baseline MR imaging), and MI is adjudicated by a study cardiologist with the criteria from the Cardiac Arrhythmia Suppression Trial and the Lipid Research Clinics Coronary Primary Prevention Trial. ${ }^{24,25}$

\section{Statistical Analysis}

Differences in continuous variables were tested with Student $t$ tests, and differences in categoric variables were assessed with $\chi^{2}$ tests. The 2 main independent variables were the small and large PVSs. Outcomes were all deaths, vascular death, MI, any stroke, and any vascular events. The small and large PVS scores were used continuously with a Poisson distribution or categorically with arbitrary cutoffs of tertiles for the small PVS score, and $\geq 2$ large PVSs for the large PVS score. To build risk models, we adjusted for total intracranial volume as a covariate. We calculated incidence rates, relative rates, and their $95 \%$ confidence intervals with Poisson regression and hazard ratios (HRs) and their 95\% CIs with Cox proportional hazard regressions, with robust sandwich error variance, adjusting for demographics, prevalent and incident vascular risk factors, and competing risks between death and the other outcomes. ${ }^{26}$ To verify that the effect of small or large PVSs was not confounded by pulsatility, we repeated fully adjusted models, substituting hypertension with $\mathrm{PP}$, mean arterial pressure, and a variable for the use of antihypertensives. We tested whether an interaction existed between small and large PVSs with PP and separately with WMHV or LPI at the time of MR imaging and performed stratified models if indicated. The statistical analysis was performed with SAS software, Version 9.4 (SAS Institute, Cary, North Carolina).

\section{RESULTS}

\section{Description of the Cohort}

After excluding those without available T1 sequences, 1228 NOMAS participants were included in this analysis (On-line Table 1). Participants were followed for an average of $9 \pm 2$ years (median, 9 years; range, $0.5-12.0$ years), contributing a total of 10,905 person-years of follow-up with negligible loss to follow-up.

Small PVSs were found in $91 \%$ of the sample (per-participant mean, $5.5 \pm 3.8$; median, 5; range, 0-22), while large PVSs were present in $42 \%$ (20\% had only 1 large PVS; $22 \%$ had $\geq 2$ large PVSs). Small PVSs were more often found in the basal ganglia (83\%), followed by subcortical white matter (79\%) and the posterior fossa $(17 \%)$. Large PVSs were more often infraputaminal (29\%) than subinsular (13\%) or subcortical (7\%). With linear regression with total intracranial volume as the outcome and adjusted for age, sex, and ethnicity, a small PVS score $(\beta=0.0001$, $P=.02)$ and large perivascular spaces total volume $(\beta=0.05, P=$ $.04)$ were associated with total intracranial volume, but a large PVS score was not $(\beta=0.60, P=.80)$.

In adjusted models, hypertension was associated with small $(\beta=0.14 \pm 0.05, P=.001)$ and large PVS scores $(\beta=0.52 \pm$ $0.11, P<.001)$. Men $(\beta=-0.13 \pm 0.05, P=.01)$ and older age $(\beta=0.05 \pm 0.01$ per year, $P=.001)$ were associated with a small PVS score, and a lower body mass index was associated with a large PVS score $(\beta=-0.03 \pm 0.01, P=.001$, On-line Table 2$)$. There was no association between brain atrophy and small PVS $(\beta=-0.01, P=.34)$ or large PVS scores (by number $\beta=0.01$, $P=.64$; or by volume $\beta=0.001, P=.21$ ).

\section{Incidence and Risk of Outcome Events}

Compared with participants in the lowest tertile of small PVSs, those in the highest tertile had a higher relative rate (RR) of all deaths (RR, 1.38; 95\% CI, 1.01-1.91), vascular death (RR, 1.87; 95\% CI, 1.12-3.14), MI (RR, 2.08; 95\% CI, 1.01-4.31), any stroke (RR, 1.79; 95\% CI, 1.03-3.11), and any vascular event (RR, 1.74; $95 \%$ CI, 1.18-2.56). There were no significant differences in the rate of events by the number of large PVSs (On-line Table 3).

In adjusted Cox proportional models, participants with higher small PVS scores had a higher risk of vascular death, MI, or any vascular events but not of any stroke (Table 1). Adjusting for WMHV and LPI attenuated the association of small PVSs with the risk of vascular death (HR, 1.04; 95\% CI, 0.98-1.09) and any vascular events (HR,1.02; 95\% CI, 0.99-1.06) but not with the risk of MI (HR, 2.15; 95\% CI, 1.07-4.33). Substituting PP, mean arterial pressure, and antihypertensive use at the time of MR imaging instead of hypertension did not change the significance of these associations.

Large PVSs were not predictors of outcome events in this sample, either by number, volume, or categorized as $\geq 2$ large PVSs. Stratifying the small and large PVS scores by anatomic location demonstrated that participants with higher small PVS scores in the basal ganglia were at a higher risk of vascular death ( $\mathrm{HR}, 1.12$; 95\% CI, 1.02-1.22) and any vascular event (HR, 1.06; 95\% CI, $1.00-1.13$ ), while a higher small PVS score in the subcortical regions conferred a higher risk of any stroke (HR, 1.08; 95\% CI, $1.00-1.16$ ) but not of MI or vascular death (Table 2).

\section{Interactions with Pulsatile Hemodynamics and Other Biomarkers of Small-Artery Disease}

Pulse pressure measured at MR imaging was an effect modifier of the association between small PVSs and vascular death $(P=.011)$, 
Table 1: Hazard ratios between perivascular spaces and outcome events ${ }^{a}$

\begin{tabular}{|c|c|c|c|c|c|}
\hline & All Deaths & Vascular Death & Myocardial Infarction & Any Stroke & Any Vascular Event \\
\hline \multicolumn{6}{|l|}{ Small PVS score } \\
\hline $\begin{array}{l}\text { Continuously } \\
\text { Categorically }\end{array}$ & 1.01, 0.98-1.04 & $1.06,1.01-1.11$ & $1.03,0.98-1.08$ & $1.04,0.98-1.10$ & $1.04,1.01-1.07$ \\
\hline First tertile & Reference & Reference & Reference & Reference & Reference \\
\hline Second tertile & $0.72,0.53-0.96$ & $1.13,0.68-1.87$ & $2.21,1.10-4.45$ & $0.96,0.54-1.72$ & $1.23,0.86-1.75$ \\
\hline Third tertile & $0.95,0.71-1.27$ & $1.34,0.80-2.23$ & $1.81,0.89-3.71$ & $1.51,0.88-2.57$ & $1.38,0.97-1.98$ \\
\hline \multicolumn{6}{|l|}{ Large PVS score } \\
\hline $\begin{array}{l}\text { Continuously } \\
\text { Categorically }\end{array}$ & $0.99,0.90-1.10$ & $0.99,0.89-1.10$ & $1.10,0.93-1.04$ & $1.07,0.88-1.28$ & $1.08,0.97-1.21$ \\
\hline$\leq 1$ & Reference & Reference & Reference & Reference & Reference \\
\hline$\geq 2$ & $1.02,0.77-1.36$ & $1.03,0.77-1.67$ & $1.40,0.83-2.36$ & $0.99,0.60-1.61$ & $1.07,0.78-1.48$ \\
\hline
\end{tabular}

${ }^{a}$ Models are adjusted for head size, motion artifacts, age, sex, ethnicity, vascular risk factors at MRI and during follow-up (hypertension, hypercholesterolemia, diabetes, and smoking), prior cardiac disease, and body mass index. Data are hazard ratios and $95 \% \mathrm{Cls}$.

Table 2: Risk of vascular events by anatomic location ${ }^{\mathrm{a}}$

\begin{tabular}{lccccc}
\hline & All Deaths & Vascular Death & Myocardial Infarction & Any Stroke & Any Vascular Event \\
\hline Small PVS score & & & & & \\
$\quad$ Basal ganglia & $1.01,0.95-1.08$ & $1.12,1.02-1.22$ & $1.06,0.94-1.19$ & $1.00,0.90-1.12$ & $1.06,1.00-1.13$ \\
$\quad$ Subcortical & $1.01,0.95-1.07$ & $1.06,0.99-1.14$ & $1.01,0.94-1.12$ & $1.08,1.00-1.16$ & $1.05,0.99-1.14$ \\
$\quad$ Posterior fossa & $1.02,0.80-1.36$ & $1.19,0.79-1.76$ & $1.26,0.83-1.91$ & $1.09,0.70-1.67$ & $1.09,0.83-1.44$ \\
Large PVS score & & & & & \\
$\quad$ Subcortical white matter & $0.68,0.43-1.07$ & $0.81,0.42-1.47$ & $1.26,0.85-1.85$ & $1.32,0.95-1.85$ & $1.08,0.79-1.47$ \\
$\quad$ Subinsular & $0.94,0.80-1.10$ & $1.21,0.92-1.39$ & $1.10,0.84-1.43$ & $1.08,0.80-1.45$ & $1.11,0.93-1.30$ \\
$\quad$ Basal ganglia supraputaminal & $1.73,1.07-2.77$ & $0.54,0.22-2.25$ & $1.17,0.31-4.37$ & $1.45,0.61-3.43$ & $0.90,0.40-1.91$ \\
$\quad$ Basal ganglia infraputaminal & $1.05,0.88-1.25$ & $1.24,0.93-1.66$ & $0.98,0.63-1.46$ & $0.92,0.70-1.22$ & $1.09,0.89-1.33$ \\
\hline
\end{tabular}

${ }^{a}$ Models are adjusted for head size, motion artifacts, age, sex, ethnicity, vascular risk factors at MRI and during follow-up (hypertension, hypercholesterolemia, diabetes, smoking), prior cardiac disease, and body mass index. Data are hazard ratios and $95 \% \mathrm{Cls}$.

\begin{tabular}{lccc}
\hline \multicolumn{5}{c}{ Table 3: Stratified risk model by tertiles of pulse pressure and systolic blood pressure } \\
\hline \multicolumn{1}{c}{ Stratified by } & Low Tertile & Middle Tertile & High Tertile $^{\mathbf{a}}$ \\
\hline $\begin{array}{l}\text { Pulse pressure at MRI } \\
\text { Small PVS score }\end{array}$ & & & \\
$\quad$ Vascular death & $1.07(0.96-1.18)$ & $1.05(0.96-1.14)$ & $1.08(1.01-1.17)$ \\
$\quad$ Any stroke & $1.01(0.90-1.13)$ & $1.03(0.90-1.18)$ & $1.07(0.98-1.16)$ \\
$\quad$ Any vascular event & $1.05(0.98-1.13)$ & $1.02(0.96-1.09)$ & $1.05(0.99-1.10)$ \\
Systolic blood pressure at MRI & & & \\
Small PVS score & & & \\
$\quad$ Vascular death & $1.08(0.99-1.18)$ & $0.96(0.86-1.08)$ & $1.11(1.04-1.20)$ \\
$\quad$ Any stroke & $1.05(0.94-1.17)$ & $0.95(0.83-1.09)$ & $1.08(1.01-1.16)$ \\
Any vascular event & $1.05(0.98-1.12)$ & $1.02(0.95-1.09)$ & $1.05(1.00-1.11)$
\end{tabular}

${ }^{a}$ Models are adjusted for head size, motion artifacts, age, sex, ethnicity, vascular risk factors at MRI and during follow-up (hypertension, hypercholesterolemia, diabetes, and smoking), prior cardiac disease, and body mass index. Data are hazard ratios and $95 \% \mathrm{Cls}$.

Table 4: Stratified risk models by white matter hyperintensities volume tertiles ${ }^{\mathrm{a}}$

\begin{tabular}{lccc}
\hline \multicolumn{1}{c}{ Stratified by } & WMH Low Tertile & WMH Middle Tertile & WMH High Tertile \\
\hline Small PVS score & & & \\
All deaths & Referent group & $1.01(1.97-1.05)$ & $1.04(1.01-1.07)$ \\
Vascular death & & $1.06(1.00-1.11)$ & $1.08(1.04-1.12)$ \\
Any stroke & & $1.01(0.94-1.08)$ & $1.07(1.02-1.12)$ \\
Any vascular event & & $1.03(0.99-1.07)$ & $1.05(1.02-1.08)$ \\
\hline
\end{tabular}

${ }^{a}$ Models are adjusted for head size, motion artifacts, age, sex, ethnicity, vascular risk factors at MRI and during follow-up (hypertension, hypercholesterolemia, diabetes, and smoking), prior cardiac disease, and body mass index. Data are hazard ratios and $95 \% \mathrm{Cls}$.

any stroke $(P=.095)$, and any vascular event $(P=.019$, On-line Table 4). In a stratified analysis, a small PVS score was predictive of vascular death, any stroke, and any vascular event only among participants in the highest tertile of $\mathrm{PP}$ and/or systolic blood pressure at the time of their MR imaging (Table 3).

There were statistical interactions between small and large PVSs with either WMHV or LPI (On-line Table 5). In stratified models, the risk of all deaths, vascular death, any stroke, and any vascular events related to the small PVS score increased in a dose-effect manner with increasing tertiles of white matter hyperintensity volume (Tables 4 and 5). The risk of MI related to small and large PVSs was higher among participants with coexisting LPI than in those without LPI. Similarly, the risk of vascular death and any vascular events related to a high PVS score was higher among participants with coexisting LPI than in those without LPI.

\section{DISCUSSION}

In this population-based study of stroke-free participants, higher incidence rates of death, vascular death, MI, stroke, and any vascular event were noted among those with the highest burden of brain small PVSs but not large PVSs. The risk of events was enhanced when PVSs coexisted with other imaging biomarkers of cerebrovascular disease, similar to what has been reported in other cohorts. ${ }^{27,28}$ Also, small PVSs predicted risk among those in the highest tertile of PP and systolic blood pressure, which we interpret as epidemiologic evidence that small PVSs may be considered imaging biomarkers of high systemic pulsatility and may represent end-organ (brain) damage of arterial stiffness.

The discrepancy noted by anatomic location and by coexistence with other biomarkers of cerebrovascular disease suggests a different pathophysiology of proximal-versus-distal small PVSs. 
Table 5: Stratified risk models by models by LPI-SBI status ${ }^{\mathrm{a}}$

\begin{tabular}{lcc}
\hline \multicolumn{1}{c}{ Stratified by } & $\begin{array}{c}\text { No LPI } \\
\text { Present }\end{array}$ & $\begin{array}{c}\text { Any LPI } \\
\text { Present }\end{array}$ \\
\hline Small PVS score & & \\
Myocardial infarction & Referent group & $1.06(1.01-1.11)$ \\
Large PVS score & & \\
Vascular death & Referent group & $1.34(1.12-1.60)$ \\
Myocardial infarction & & $1.27(1.01-1.58)$ \\
Any vascular event & & $1.18(1.04-1.35)$ \\
\hline
\end{tabular}

a Models are adjusted for head size, motion artifacts, age, sex, ethnicity, vascular risk factors at MRI and during follow-up (hypertension, hypercholesterolemia, diabetes, and smoking), prior cardiac disease, and body mass index. Data are hazard ratios and 95\% Cls.

For example, as the pulse-wave pressure dissipates centrifugally from the aorta, progressive arterial stiffness limits attenuation of the pulse-wave as it travels into branching arteries leading to end organs. ${ }^{29}$ Low-resistance organs like the brain are especially susceptible to damage related to high pulsatility. ${ }^{30}$ As the pulse-wave enters the brain, it encounters first the lenticulostriate penetrating branches of the middle cerebral arteries supplying the subtantia innominata and the basal ganglia and, posteriorly, the vertebrobasilar system that supplies the brain stem and the cerebellum. The abrupt change in caliber from large to penetrating arteries renders these smaller vessels susceptible to systemic hemodynamic stresses, and it may explain why small PVSs in these proximal locations better predict vascular outcomes other than stroke. ${ }^{31,32}$ For example, NOMAS participants with PVSs in the posterior fossa had a nominal 26\% higher risk of MI per PVS noted, while the risk of MI with evidence of subcortical small perivascular spaces was only $1 \%$ higher. Some studies have shown that subcortical (distal) PVSs are more common in nonvascular dementias and multiple sclerosis, while basal ganglia (proximal) PVSs are common with vascular dementias and hypertension. ${ }^{10,33,34}$ Another possible explanation for the disparities in the rates of PVS by location may be related to the double meningeal wrapping of penetrating arteries in the basal ganglia compared with single-layered coating in other locations, ${ }^{3}$ which may affect the drainage efficacy of interstitial fluids. Growing interest has been paid to the interplay among the glymphatic drainage system, PVSs, and arachnoid granulations in the drainage of interstitial brain fluid, ${ }^{4}$ but it remains unclear in humans whether glymphatic drainage differs by anatomic location.

Another relevant finding from our work is the lack of correlation between large PVSs and vascular risk, despite their association with hypertension. Initially, we theorized that large PVSs could represent an extreme on a continuum starting with small PVSs; consequently, we hypothesized that large PVSs might confer greater vascular risk. However, the data presented here only suggest an increased risk of vascular events related to large PVSs among those with coexisting LPI. Consequently, large PVSs might be anatomic variants that occasionally may come to clinical attention if they enlarge enough to cause compressive symptoms, but they may not be good biomarkers of vascular risk in the general population (unlike small PVSs or LPI). ${ }^{35,36}$ These data also serve as validation of the effort to classify PVSs into distinct pathologic subtypes ${ }^{5}$ and should motivate researchers to systematically separate large PVSs from infarcts. ${ }^{37}$
The results presented here prospectively validate small VPSs as imaging biomarkers of vascular risk in an unselected population. We have attempted to systematically differentiate PVSs from infarcts as other groups have, ${ }^{10,14}$ but we have incorporated pathologic information that we believe may improve the accuracy of our methods. We lack pathology of these brains, which limits the claim that our method is valid and accurate. The reliability of ratings of brain parenchymal lesions, particularly $<3 \mathrm{~mm}$, is less than ideal, even in large epidemiologic studies such as NOMAS, Atherosclerosis Risk in Communities, and others. ${ }^{6,10,38}$ The error in measurement may explain the lack of statistical significance in some of our models as it pertains to small PVSs. Because large PVSs are larger and easier to quantify, error is unlikely to be the explanation for the lack of association between large PVSs and outcomes. Automatization of the rating of small and large PVSs and LPI should be a priority in this field, but it appears daunting, given the complexities of the brain anatomy and the conflicting data among studies. The use of PP and systolic blood pressure as biomarkers of arterial stiffness is not unprecedented. ${ }^{39-41}$ The lack of more accurate measurements of arterial stiffness, however, is a limitation of our methods.

\section{CONCLUSIONS}

We present evidence that individuals with a higher burden of small PVSs on brain MR imaging are at a higher risk of vascular events, especially if their PP or systolic blood pressure is elevated. Among individuals with subcortical but not deep small perivascular spaces who also have coexpression of white matter hyperintensity and LPI, the risk of stroke is higher. These results emphasize the need for an integrated approach to the study of brain arterial disease that takes into account systemic and intracranial anatomic variations among individuals. By gaining this pathophysiologic insight, we may be able to propose novel therapies for palliating the effects of cerebrovascular disorders in the general population.

Disclosures: Jose Gutierrez-RELATED: Grant: National Institute of Neurological Disorders and Stroke*; UNRELATED: Consultancy: Prophase, Pfizer; Expert Testimony: medico-legal testimony; Grants/Grants Pending: National Institute of Neurological Disorders and Stroke*; Payment for Development of Educational Presentations: Prophase. Mitchell S.V. Elkind-RELATED: Grant: National Institutes of Health/National Institute of Neurological Disorders and Stroke, Comments: R01 29993 for the Northern Manhattan Study*; UNRELATED: Board Membership: American Heart Association/American Stroke Association, Comments: national, regional, and local boards; Consultancy: Boehringer-Ingelheim, Bristol-Myers Squibb-Pfizer Partnership, Sanofi-Regeneron, BioTelemetry/CardioNet, Comments: BoehringerIngelheim, dabigatran; Bristol-Myers Squibb-Pfizer Partnership, apixaban; Sanofi-Regeneron, PCSK9 inhibitors; Biotelemetry/Cardionet, cardiac monitoring for paroxysmal atrial fibrillation; Expert Testimony: Merck/Organon, Comments: NuvaRing; Royalties: UpToDate, Comments: chapters on cryptogenic stroke and hemicraniectomy. Marco Di Tullio-RELATED: Grant: National Institutes of Health/National Institute of Neurological Disorders and Stroke, Comments: research grants to support NOMAS*; UNRELATED: Grants/Grants Pending: National Institutes of Health/ National Institute of Neurological Disorders and Stroke, Comments: R01 research grant to study the frequency of asymptomatic atrial fibrillation in the community. ${ }^{*}$ Tatjana Rundek—RELATED: Grant: National Institutes of Health*. Ralph L. SaccoRELATED: Grant: Northern Manhattan Study, National Institute of Neurological Disorders and Stroke*; UNRELATED: Board Membership: American Academy of Neurology officer; Consultancy: Boehringer-Ingelheim. Clinton B. Wright-RELATED: Grant: National Institutes of Health/National Institute of Neurological Disorders and Stroke, Comments: R01 NS 29993*; UNRELATED: Royalties: UpToDate.com for 2 chapters on vascular dementia. *Money paid to the institution. 


\section{REFERENCES}

1. Zhang ET, Inman CB, Weller RO. Interrelationships of the pia mater and the perivascular (Virchow-Robin) spaces in the human cerebrum. J Anat 1990;170:111-23 Medline

2. Fleury J, Gherardi R, Poirier J. The perivascular spaces of the central nervous system: histophysiological data. Ann Pathol 1984;4:245-47 Medline

3. Pollock $\mathrm{H}$, Hutchings $\mathrm{M}$, Weller RO, et al. Perivascular spaces in the basal ganglia of the human brain: their relationship to lacunes. $J$ Anat 1997;191(pt 3):337-46 CrossRef Medline

4. Louveau A, Smirnov I, Keyes TJ, et al. Structural and functional features of central nervous system lymphatic vessels. Nature 2015; 523:337-41 CrossRef Medline

5. Poirier J, Derouesne C. Cerebral lacunae: a proposed new classification. Clin Neuropathol 1984;3:266 Medline

6. Gutierrez J, Elkind MS, Cheung K, et al. Pulsatile and steady components of blood pressure and subclinical cerebrovascular disease: the Northern Manhattan Study. J Hypertens 2015;33:2115-22 CrossRef Medline

7. Wuerfel J, Haertle M, Waiczies $H$, et al. Perivascular spaces: MRI marker of inflammatory activity in the brain? Brain 2008;131: 2332-40 CrossRef Medline

8. Millen JW, Woollam DH. The reticular perivascular tissue of the centra nervous system. J Neurol Neurosurg Psychiatry 1954;17: 286-94 CrossRef Medline

9. Gutierrez J, Rundek T, Ekind MS, et al. Perivascular spaces are associated with atherosclerosis: an insight from the Northern Manhattan Study. AJNR Am J Neuroradiol 2013;34:1711-16 CrossRef Medline

10. Zhu YC, Tzourio C, Soumaré A, et al. Severity of dilated VirchowRobin spaces is associated with age, blood pressure, and MRI markers of small vessel disease: a population-based study. Stroke 2010;41: 2483-90 CrossRef Medline

11. Doubal FN, MacLullich AM, Ferguson KJ, et al. Enlarged perivascular spaces on MRI are a feature of cerebral small vessel disease. Stroke 2010;41:450-54 CrossRef Medline

12. Awad IA, Johnson PC, Spetzler RF, et al. Incidental subcortical lesions identified on magnetic resonance imaging in the elderly, II: postmortem pathological correlations. Stroke 1986;17:1090-97 CrossRef Medline

13. Pullicino PM, Miller LL, Alexandrov AV, et al. Infraputaminal 'lacunes': clinical and pathological correlations. Stroke 1995;26: 1598-602 CrossRef Medline

14. Heier LA, Bauer CJ, Schwartz L, et al. Large Virchow-Robin spaces: MR-clinical correlation. AJNR Am J Neuroradiol 1989;10:929-36 Medline

15. Bradbury MW, Cserr HF, Westrop RJ. Drainage of cerebral interstitial fluid into deep cervical lymph of the rabbit. Am J Physiol 1981; 240:F329-36 Medline

16. Rollins NK, Deline C, Morriss MC. Prevalence and clinical significance of dilated Virchow-Robin spaces in childhood. Radiology 1993;189:53-57 CrossRef Medline

17. Jungreis CA, Kanal E, Hirsch WL, et al. Normal perivascular spaces mimicking lacunar infarction: MR imaging. Radiology 1988;169: 101-04 CrossRef Medline

18. Kothari RU, Brott T, Broderick JP, et al. The ABCs of measuring intracerebral hemorrhage volumes. Stroke 1996;27:1304-05 CrossRef Medline

19. Bokura H, Kobayashi S, Yamaguchi S. Distinguishing silent lacunar infarction from enlarged Virchow-Robin spaces: a magnetic resonance imaging and pathological study. J Neurol 1998;245:116-22 CrossRef Medline

20. Adachi M, Hosoya T, Haku T, et al. Dilated Virchow-Robin spaces: MRI pathological study. Neuroradiology 1998;40:27-31 CrossRef Medline

21. Dong C, Nabizadeh N, Caunca M, et al. Cognitive correlates of white matter lesion load and brain atrophy: the Northern Manhattan Study. Neurology 2015;85:441-49 CrossRef Medline
22. Kloppenborg RP, Nederkoorn PJ, Grool AM, et al; SMART Study Group. Cerebral small-vessel disease and progression of brain atrophy: the SMART-MR study. Neurology 2012;79:2029-36 CrossRef Medline

23. Boden-Albala B, Roberts ET, Bazil C, et al. Daytime sleepiness and risk of stroke and vascular disease: findings from the Northern Manhattan Study (NOMAS). Circ Cardiovasc Qual Outcomes 2012;5: 500-07 CrossRef Medline

24. Echt DS, Liebson PR, Mitchell LB, et al. Mortality and morbidity in patients receiving encainide, flecainide, or placebo: the Cardiac Arrhythmia Suppression Trial. N Engl J Med 1991;324:781-88 CrossRef Medline

25. Schaefer EJ, Lamon-Fava S, Jenner JL, et al. Lipoprotein(a) levels and risk of coronary heart disease in men: the Lipid Research Clinics Coronary Primary Prevention Trial. JAMA 1994;271:999-1003 Medline

26. So Y, Lin G, Johnston G. Using the PHREG procedure to analyze competing-risks data. In: Proceedings of the SAS Global Forum 2015 Conference. Cary, NC: SAS Institute Inc; 2015. http://support.sas. com/resources/papers/proceedings15/SAS1855-2015.pdf. Accessed September 5, 2016

27. Huijts M, Duits A, van Oostenbrugge RJ, et al. Accumulation of MRI markers of cerebral small vessel disease is associated with decreased cognitive function: a study in first-ever lacunar stroke and hypertensive patients. Front Aging Neurosci 2013;5:72 CrossRef Medline

28. Staals J, Makin SD, Doubal FN, et al. Stroke subtype, vascular risk factors, and total MRI brain small-vessel disease burden. Neurology 2014;83:1228-34 CrossRef Medline

29. Mitchell GF. Arterial stiffness and wave reflection: biomarkers of cardiovascular risk. Artery Res 2009;3:56-64 CrossRef Medline

30. Kalvach $\mathrm{P}$, Gregová D, Skoda O, et al. Cerebral blood supply with aging: normal, stenotic and recanalized. J Neurol Sci 2007;257: 143-48 CrossRef Medline

31. Cole FM, Yates PO. Comparative incidence of cerebrovascular lesions in normotensive and hypertensive patients. Neurology 1968; 18:255-59 CrossRef Medline

32. Hughes W. Hypothesis. Lancet 1965;286:19-21 CrossRef

33. Varma AR, Laitt R, Lloyd JJ, et al. Diagnostic value of high signal abnormalities on T2 weighted MRI in the differentiation of Alzheimer's, frontotemporal and vascular dementias. Acta Neurol Scand 2002;105:355-64 CrossRef Medline

34. Etemadifar M, Hekmatnia A, Tayari N, et al. Features of VirchowRobin spaces in newly diagnosed multiple sclerosis patients. Eur $J$ Radiol 2011;80:e104-08 CrossRef Medline

35. Salzman KL, Osborn AG, House P, et al. Giant tumefactive perivascular spaces. AJNR Am J Neuroradiol 2005;26:298-305 Medline

36. Papayannis CE, Saidon P, Rugilo CA, et al. Expanding Virchow Robin spaces in the midbrain causing hydrocephalus. AJNR Am J Neuroradiol 2003;24:1399-403 Medline

37. Gupta A, Giambrone AE, Gialdini G, et al. Silent brain infarction and risk of future stroke: a systematic review and meta-analysis. Stroke 2016;47:719-25 CrossRef Medline

38. Bezerra DC, Sharrett AR, Matsushita K, et al. Risk factors for lacune subtypes in the Atherosclerosis Risk in Communities (ARIC) Study. Neurology 2012;78:102-08 CrossRef Medline

39. Mitchell GF, van Buchem MA, Sigurdsson S, et al. Arterial stiffness, pressure and flow pulsatility and brain structure and function: the Age, Gene/Environment Susceptibility-Reykjavik study. Brain 2011;134:3398-407 CrossRef Medline

40. Franklin SS, Khan SA, Wong ND, et al. Is pulse pressure useful in predicting risk for coronary heart disease? The Framingham Heart Study. Circulation 1999;100:354-60 CrossRef Medline

41. McEniery CM, Yasmin, Hall IR, et al; ACCT Investigators. Normal vascular aging: differential effects on wave reflection and aortic pulse wave velocity: the Anglo-Cardiff Collaborative Trial (ACCT). J Am Coll Cardiol 2005;46:1753-60 CrossRef Medline 